\title{
24(S)-Hydroxycholesterol induces ER dysfunction-mediated unconventional cell death
}

\author{
Yasuomi Urano ${ }^{1}$, Diep-Khanh Ho Vo $\mathbb{D}^{1}$, Araki Hirofumi ${ }^{1}$ and Noriko Noguchi ${ }^{1}$
}

\begin{abstract}
Endoplasmic reticulum (ER) stress induced by disruption of protein folding activates the unfolded protein response (UPR), which while generally pro-survival in effect can also induce cell death under severe ER stress. 24(S)hydroxycholesterol (24S-OHC), which is enzymatically produced in the ER of neurons, plays an important role in maintaining brain cholesterol homeostasis but also shows neurotoxicity when subjected to esterification by acyl-CoA: cholesterol acyltransferase 1 (ACAT1) in the ER. In this study, we demonstrated that the accumulation of 24S-OHC esters in human neuroblastoma SH-SY5Y cells evoked the UPR with substantially no pro-survival adaptive response but with significant activation of pro-death UPR signaling via regulated IRE1-dependent decay (RIDD). We further found that accumulation of 24S-OHC esters caused disruption of ER membrane integrity and release of ER luminal proteins into cytosol. We also found that de novo synthesis of global proteins was robustly suppressed in 24S-OHC-treated cells. Collectively, these results show that ER dysfunction and the accompanying RIDD-mediated pro-death UPR signaling and global protein synthesis inhibition are responsible for 24S-OHC ester-induced unconventional cell death.
\end{abstract}

\section{Introduction}

Upon accumulation of unfolded/misfolded proteins in the endoplasmic reticulum (ER) - a condition referred to as ER stress-cells activate an adaptive response-this response being referred to as the unfolded protein response (UPR) - to restore ER homeostasis and maintain the fidelity of protein-folding ${ }^{1}$. In mammalian cells, the UPR comprises three major signaling pathways, which are respectively mediated by inositol-requiring enzyme 1 (IRE1), protein kinase RNA-like ER kinase (PERK), and activating transcription factor 6 (ATF6). The UPR processes include induction of ER chaperones, inhibition of protein synthesis, and stimulation of retrograde transport of misfolded proteins from the ER into the cytosol for

\footnotetext{
Correspondence: Yasuomi Urano (yurano@mail.doshisha.ac.jp) or Noriko Noguchi (nnoguchi@mail.doshisha.ac.jp)

'Department of Medical Life Systems, Faculty of Life and Medical Sciences, Doshisha University, Kyoto 610-0394, Japan

These authors contributed equally: Yasuomi Urano, Diep-Khanh Ho Vo Edited by I. Lavrik
}

ubiquitination and destruction by ER-associated degradation $(E R A D)^{2}$. However, under unresolvable ER stress conditions, the UPR represses the adaptive response and triggers cell death ${ }^{3-6}$.

On activation of IRE1, phosphorylated IRE1 becomes an active endoribonuclease (RNase) that cleaves an intron of $X$-box binding protein 1 (XBP1) mRNA, resulting in the translation of bZIP-containing transcription factor $\mathrm{XBP} 1 \mathrm{~s}^{1}$. XBP1s induces the expression of several genes involved in the UPR to activate pro-survival mechanisms. IRE1 RNase activity also contributes to posttranscriptional degradation of a subset of ER-localized mRNAs through a process known as regulated IRE1dependent decay (RIDD) ${ }^{7-9}$. Although RIDD may help to reduce the folding load of nascent proteins and alleviate ER stress as a pro-survival mechanism, continuous decay of RIDD substrates by unmitigated ER stress leads to prodeath outputs ${ }^{4,10}$. Activated IRE1 also promotes apoptosis through the activation of apoptosis signal-regulated kinase 1 (ASK1; also known as MAP3K5), JUN N-

\section{(c) 2019 The Author(s).}


terminal kinase (JNK), and p38 MAPK. Activation of PERK by autophosphorylation induces pro-survival signaling and pro-apoptotic signaling. Activated PERK phosphorylates eukaryotic translation initiator factor $2 \alpha$ (eIF $2 \alpha)$ and causes general translational attenuation which is a pro-survival process, as it reduces the number of proteins entering the $\mathrm{ER}^{11}$. In addition, phosphorylation of eIF2 $\alpha$ also induces the specific translation of ATF4. ATF4 controls the expression of genes that encode not only cytoprotective proteins but also pro-apoptotic proteins, including C/EBP-homologous protein $(\mathrm{CHOP})^{12}$. ATF6 is a type II transmembrane protein containing bZIP transcription factor in its cytosolic domain. Upon occurrence of ER stress, ATF6 translocates to the Golgi apparatus, where it is cleaved by site- 1 protease and site- 2 protease. The cleaved cytosolic domain of ATF6 activates transcription of target genes such as ER chaperones. There is growing evidence that not only accumulation of unfolded/misfolded proteins in the ER lumen, but also alterations in membrane lipid desaturation and aberrant phospholipid composition may also be potent in activating the $\mathrm{UPR}^{13,14}$. There is, however, little known at present about whether oxidation products of lipids might activate the UPR.

24(S)-hydroxycholesterol (24S-OHC) is one of the enzymatic oxidation products of cholesterol and plays an important role in maintaining brain cholesterol homeostasis $^{15-18}$. While $24 \mathrm{~S}-\mathrm{OHC}$ has important physiological and protective functions in the brain, several lines of evidence suggest that dysregulation of $24 \mathrm{~S}-\mathrm{OHC}$ metabolism in the brain may contribute to the development of neurodegenerative diseases such as Alzheimer's disease (AD) and Parkinson's disease $(\mathrm{PD})^{19-26}$. Furthermore, we and other groups have shown that $24 \mathrm{~S}-\mathrm{OHC}$ possesses a potent neurotoxicity that may be involved in the etiology of neurodegenerative disease ${ }^{27,28}$. We have previously demonstrated that $24 \mathrm{~S}-\mathrm{OHC}$ elicits caspase-independent cell death in human neuroblastoma SH-SY5Y cells, and rat primary cortical neuronal cells not expressing caspase- $8^{28}$. 24S-OHC-induced cell death is partially but significantly suppressed by Necrostatin-1 (Nec-1), an inhibitor of receptor interacting serine/threonine kinase 1 (RIPK1) or knockdown of RIPK1. However, as necroptosis is a form of regulated necrotic cell death that depends on MLKL, RIPK3, and (at least in some settings) on the kinase activity of RIPK $1^{29}$, and since we subsequently showed that RIPK1, but neither RIPK3 nor MLKL, is expressed in SH-SY5Y cells ${ }^{30}$, we considered that the type of cell death induced by $24 \mathrm{~S}-\mathrm{OHC}$ in SH-SY5Y cells is necroptosislike.

Acyl-CoA:cholesterol acyltransferase 1 (ACAT1), an ER-resident enzyme, catalyzes the esterification of free cholesterol to form cholesteryl esters ${ }^{31}$. We found that ACAT1 also utilizes 24S-OHC and long-chain unsaturated fatty acid as substrates to form $24 \mathrm{~S}-\mathrm{OHC}$ ester $^{32,33}$. We further found that accumulation of 24S$\mathrm{OHC}$ esters leads to formation of atypical lipid droplet (LD)-like structures coupled with an enlarged membrane structure that appears to be a swollen ER structure ${ }^{33}$. Since ACAT inhibitor or ACAT1 siRNA suppresses both 24S-OHC-induced LD-like structure formation and cell death, we concluded that ACAT1-catalyzed 24S-OHC esterification and formation of atypical LD-like structures having abnormal ER morphology are initial key events in 24S-OHC-induced cell death; however, the specific mechanism by which $24 \mathrm{~S}-\mathrm{OHC}$ esterification activates cell death signaling still remains to be elucidated.

In this study, we found that esterification of $24 \mathrm{~S}-\mathrm{OHC}$ evoked the UPR but the downstream pro-survival adaptive response was not substantially activated, finding instead that RIDD is implicated in 24S-OHC-induced cell death. We also demonstrate that accumulation of 24S$\mathrm{OHC}$ esters caused disruption of ER membrane integrity, resulting in the release of a number of ER-resident proteins into cytosol and the suppression of de novo protein synthesis. Taken together, we conclude that ER dysfunction, and the accompanying pro-death UPR signaling and protein synthesis inhibition, are responsible for cell death induced by ACAT1-catalized 24S-OHC esterification.

\section{Results \\ Accumulation of 24S-OHC esters activated the UPR in SH-SY5Y cells}

To investigate the activation of UPR signaling by 24S$\mathrm{OHC}$, we first examined IRE1 autophosphorylation by immunoblotting. In a control experiment, the wellestablished ER stress inducer thapsigargin, which inhibits ER $\mathrm{Ca}^{2+}$-ATPase, induced phosphorylation of IRE1 $\alpha$ as confirmed by observation of mobility shift of the IRE1 $\alpha$ band in SDS-PAGE as compared with vehicle condition in SH-SY5Y cells (Fig. 1a). The same shift in the IRE1 $\alpha$ band was observed in cells treated with $50 \mu \mathrm{M} 24 \mathrm{~S}-\mathrm{OHC}$ for $6 \mathrm{~h}$, suggesting that $24 \mathrm{~S}-\mathrm{OHC}$ treatment induced IRE1 $\alpha$ phosphorylation. 24S-OHC-induced IRE1 $\alpha$ phosphorylation was inhibited by cotreatment with F12511 but not by Nec-1 (Fig. 1a). We further found that XBP1 splicing was induced in cells treated with $24 \mathrm{~S}-\mathrm{OHC}$ in similar fashion as was observed with thapsigargin treatment (Fig. 1b). 24S-OHC-induced XBP1 splicing was also inhibited by cotreatment with F12511. However, XBP1s protein expression was less remarkably induced in 24S-OHCtreated cells than in thapsigargin-treated cells (Fig. 1c), suggesting that IRE1 $\alpha$ was activated but that downstream $\mathrm{XBP} 1 \mathrm{~s}$ was not substantially activated in $24 \mathrm{~S}-\mathrm{OHC}$ treated cells.

We also found that there was phosphorylation of PERK as demonstrated by the occurrence of mobility shift and reduction in the amount of full-length ATF6, which 


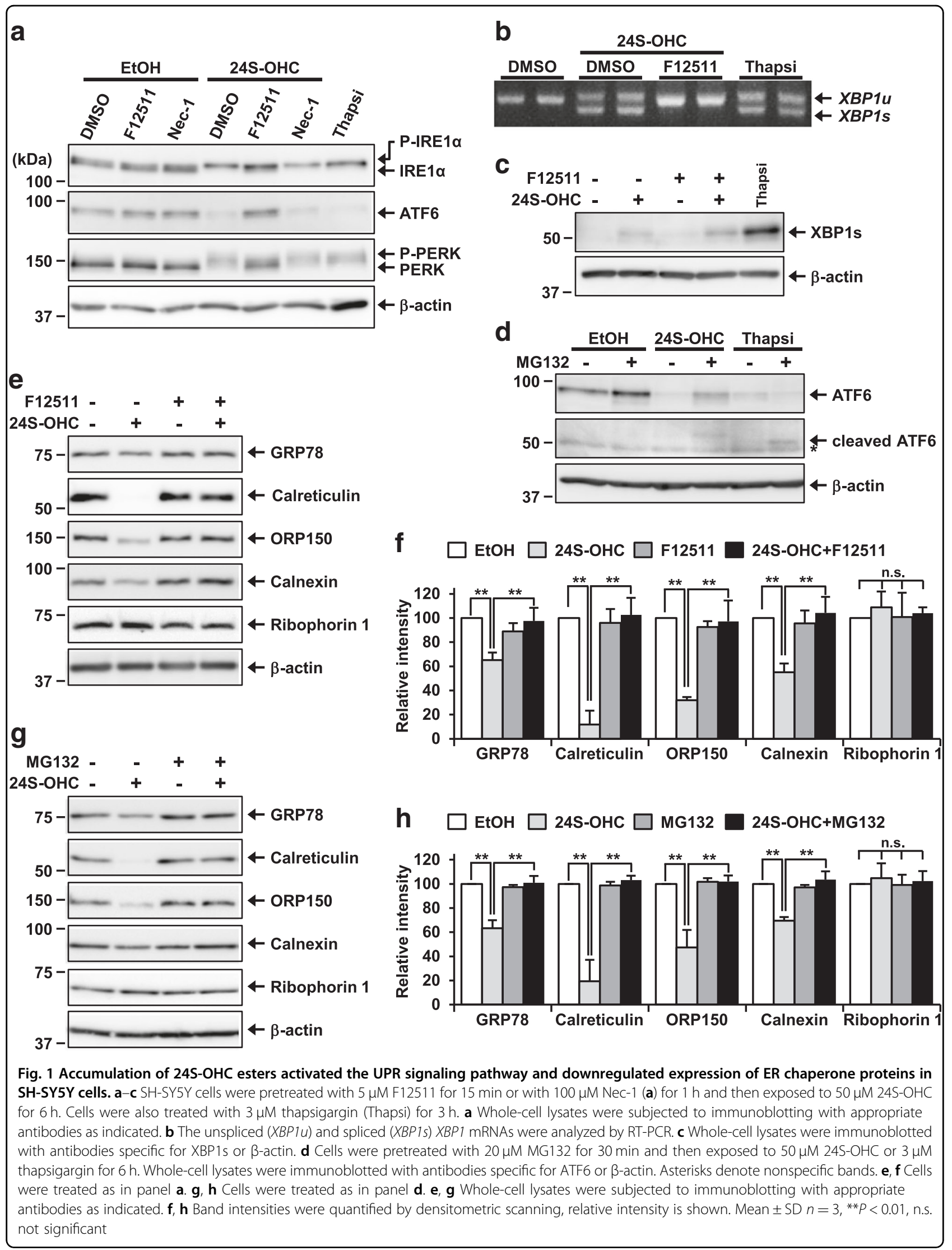


occurred in cells treated with $24 \mathrm{~S}-\mathrm{OHC}$ in similar fashion as was observed with thapsigargin treatment (Fig. 1a). Similar to our observations with respect to IRE1 $\alpha$, these changes were found to be suppressed by cotreatment with F12511, but not by Nec-1. Because the cleaved form of ATF6 is relatively unstable due to proteasomal degradation $^{34}$, we also examined activation of ATF6 in the presence of the proteasome inhibitor MG132, finding that the cleaved ATF6 was observed in cells treated with thapsigargin in the presence of MG132, but that uncleaved full-length ATF6 was observed in cells treated with 24S-OHC (Fig. 1d), suggesting that 24S-OHCinduced reduction of full-length ATF6 was not due to processing, but was instead due to proteasomal degradation.

We further found that expression of ER chaperone proteins (glucose-regulated protein $78 \mathrm{kDa}$ (BiP/GRP78), calreticulin, ORP150, and calnexin) but not ribophorin 1 was reduced in $24 \mathrm{~S}-\mathrm{OHC}$-treated cells, and that this reduction was suppressed by cotreatment with F12511 (Fig. 1e, f). We also found that this reduction was inhibited by cotreatment with MG132 (Fig. 1g, h), suggesting that 24S-OHC-induced downregulation of ER chaperone proteins was due to proteasomal degradation. Timecourse experiments revealed that IRE1 $\alpha$ phosphorylation occurred substantially, simultaneously with reduction in the amount of calreticulin (Fig. S1). Collectively, these data indicate that ACAT1-mediated 24S-OHC esterification induces ER stress, leading to activation of UPR signaling pathways, but that pro-survival mechanisms are not substantially activated in SH-SY5Y cells.

\section{Upregulation of CHOP expression was not involved in 24S-OHC-induced cell death in SH-SY5Y cells}

To investigate whether activation of pro-death UPR signaling was implicated in 24S-OHC-induced cell death, we first examined the induction of ATF4 and CHOP in SH-SY5Y cells, the results showing that ATF4 and CHOP expression was only moderately induced in 24S-OHCtreated cells as compared with the more pronounced expression, thereof observed in thapsigargin-treated cells (Fig. 2a). Furthermore, when 24S-OHC-induced CHOP upregulation was suppressed by CHOP siRNA (Fig. 2b), we found that cell death was not suppressed (Fig. 2c),

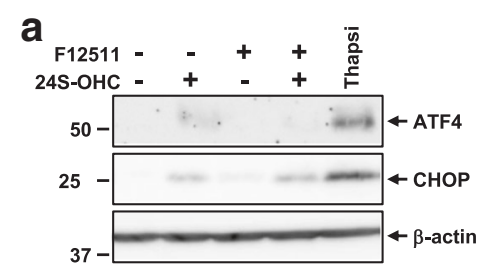

d

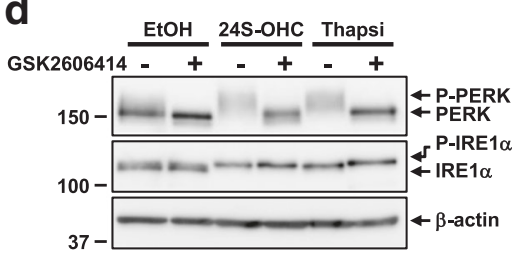

f

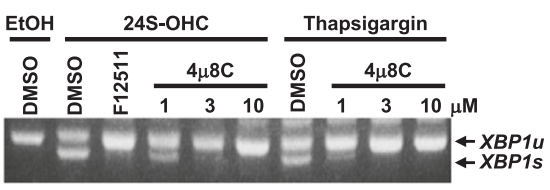

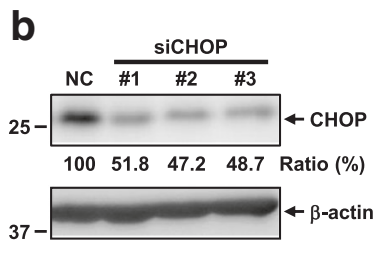
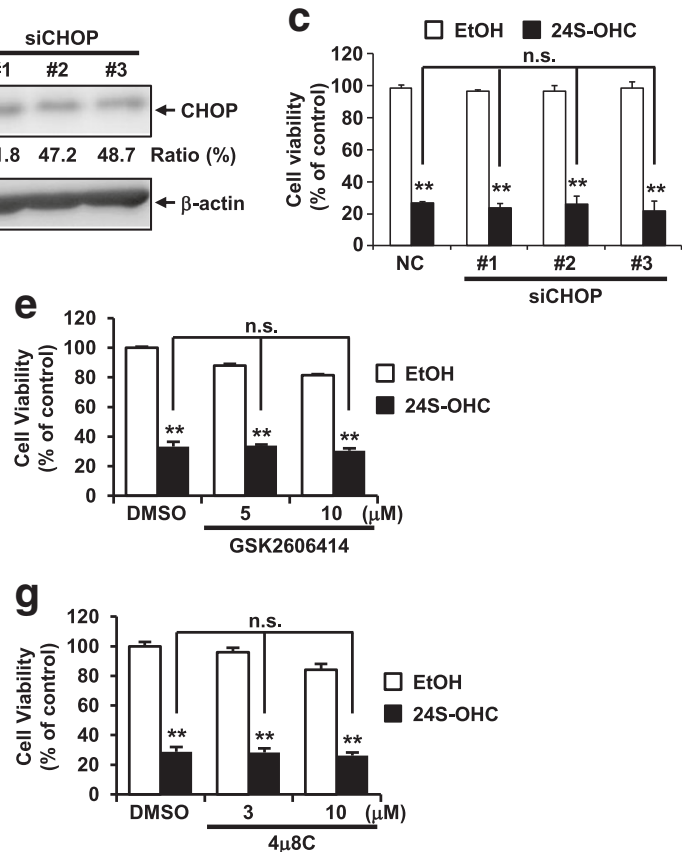

Fig. 2 PERK and IRE1-XBP1 axes were not involved in 24S-OHC-induced cell death in SH-SY5Y cells. a SH-SY5Y cells were treated as in Fig. 1a. Whole-cell lysates were immunoblotted with antibodies specific for ATF4, CHOP, or $\beta$-actin. b, c Cells were transfected with CHOP (siCHOP \#1-\#3) or negative control (NC) siRNA oligo for $24 \mathrm{~h}$. b Whole-cell lysates were immunoblotted with antibodies specific for CHOP or $\beta$-actin. Relative expression levels of CHOP are shown. c The cells were exposed to $50 \mu \mathrm{M} 24 \mathrm{~S}-\mathrm{OHC}$ for $24 \mathrm{~h}$. Cell viability was measured by LDH assay. ${ }^{* *} P<0.01$, when compared with cells treated with vehicle or among 24S-OHC-treated groups. d Cells were pretreated with $5 \mu \mathrm{M}$ GSK2606414 for 30 min then exposed to $50 \mu \mathrm{M}$ $24 \mathrm{~S}-\mathrm{OHC}$ or $3 \mu \mathrm{M}$ thapsigargin for $6 \mathrm{~h}$. Whole-cell lysates were immunoblotted with antibodies specific for PERK, IRE1a, or $\beta$-actin. e Cells were pretreated with 5 or $10 \mu \mathrm{M}$ GSK2606414 for 30 min then exposed to $50 \mu \mathrm{M} 24 \mathrm{~S}-\mathrm{OHC}$ for $24 \mathrm{~h}$. Cell viability was measured by WST-8 assay. ${ }^{* *} P<0.01$. f Cells were pretreated with $5 \mu \mathrm{M}$ F12511 for $15 \mathrm{~min}$ or with 1-10 $\mathrm{MM} 4 \mu \mathrm{C}$ for $1 \mathrm{~h}$ then exposed to $50 \mu \mathrm{M} 24 \mathrm{~S}-\mathrm{OHC}$ for $6 \mathrm{~h}$ or $1 \mu \mathrm{M}$ thapsigargin for $3 \mathrm{~h}$, respectively. XBP1 mRNAs were analyzed by RT-PCR. g Cells were pretreated with 3 or $10 \mu \mathrm{M} 4 \mu 8 \mathrm{C}$ for $1 \mathrm{~h}$ and then exposed to $50 \mu \mathrm{M} 24 \mathrm{~S}-\mathrm{OHC}$ for $24 \mathrm{~h}$. Cell viability was measured by WST-8 assay. ${ }^{* *} P<0.01$ 
suggesting that $\mathrm{CHOP}$ induction is not involved in the 24S-OHC-induced cell death machinery.

PERK, IRE1-XBP1, and IRE1-ASK1 axes were not involved in 24S-OHC-induced cell death in SH-SY5Y cells

We then evaluated the effect of the PERK inhibitor GSK2606414, the results showing that GSK2606414 treatment inhibited autophosphorylation of PERK in cells treated with either $24 \mathrm{~S}-\mathrm{OHC}$ or thapsigargin (Fig. 2d). As expected, 24S-OHC-induced IRE1 $\alpha$ phosphorylation was not inhibited by GSK2606414 treatment. Under the conditions tested, 24S-OHC-induced cell death was not suppressed by GSK2606414 (Fig. 2e), suggesting that the PERK activation was not involved in $24 \mathrm{~S}-\mathrm{OHC}$-induced cell death.

We next evaluated the effects of the selective IRE1 $\alpha$ RNase inhibitor 8-formyl-7-hydroxy-4-methylcoumarin $(4 \mu 8 \mathrm{C})$, results showing that $4 \mu 8 \mathrm{C}$ inhibited XBP1 splicing in a concentration-dependent manner in cells treated with either $24 \mathrm{~S}-\mathrm{OHC}$ or thapsigargin (Fig. 2f), but that $4 \mu 8 \mathrm{C}$ did not inhibit $24 \mathrm{~S}-\mathrm{OHC}$-induced cell death (Fig. 2g). These results indicate that inhibition of IRE1 $\alpha-$ mediated XBP1 splicing by $4 \mu 8 \mathrm{C}$ did not prevent $24 \mathrm{~S}$ $\mathrm{OHC}$-induced cell death in SH-SY5Y cells.

We also evaluated the effect of the selective inhibitor of ASK1 (NQDI-1), p38 (SB203580), or JNK (SP600125) on 24S-OHC-induced cell death, the results showing that neither NQDI-1 nor SB203580 nor SP600125 was able to prevent 24S-OHC-induced cell death (Fig. S2A-C), suggesting that neither ASK1 nor p38 or JNK is implicated in 24S-OHC-induced cell death.

As the small molecular chemical chaperone 4-phenylbutyric acid (4-PBA) was reported to protect against ER stress-mediated neuronal cell death by aiding in protein folding ${ }^{35,36}$, we tested the effects of 4-PBA on 24S-OHC-induced cell death, finding as a result that cotreatment with $1 \mathrm{mM}$ of 4-PBA significantly mitigated thapsigargin-induced cell death, but did not affect $24 S$ OHC-induced cell death (Fig. S2D), suggesting that the increase in ER folding capacity produced by 4-PBA was ineffective in decreasing 24S-OHC-induced cell death.

\section{Inhibition of RIDD mitigated 24S-OHC-induced cell death in SH-SY5Y cells}

We next investigated whether RIDD was implicated in 24S-OHC-induced cell death. Since RIDD targets multiple mRNA substrates ${ }^{37-39}$, we evaluated the expression levels of a series of RIDD substrates including ANGPTL3, BLOS1, COL6, PDGFRB, and $S C A R A 3$, the results showing that the expression of all genes examined was significantly reduced in cells treated with $24 \mathrm{~S}-\mathrm{OHC}$ for $6 \mathrm{~h}$ compared to the vehiclecontrol condition in SH-SY5Y cells (Fig. 3a), suggesting that $24 \mathrm{~S}-\mathrm{OHC}$ treatment activated the RIDD pathway. Downregulation of all genes tested was inhibited by cotreatment with F12511, indicating that activation of RIDD occurred in response to ACAT1-mediated 24S$\mathrm{OHC}$ esterification.

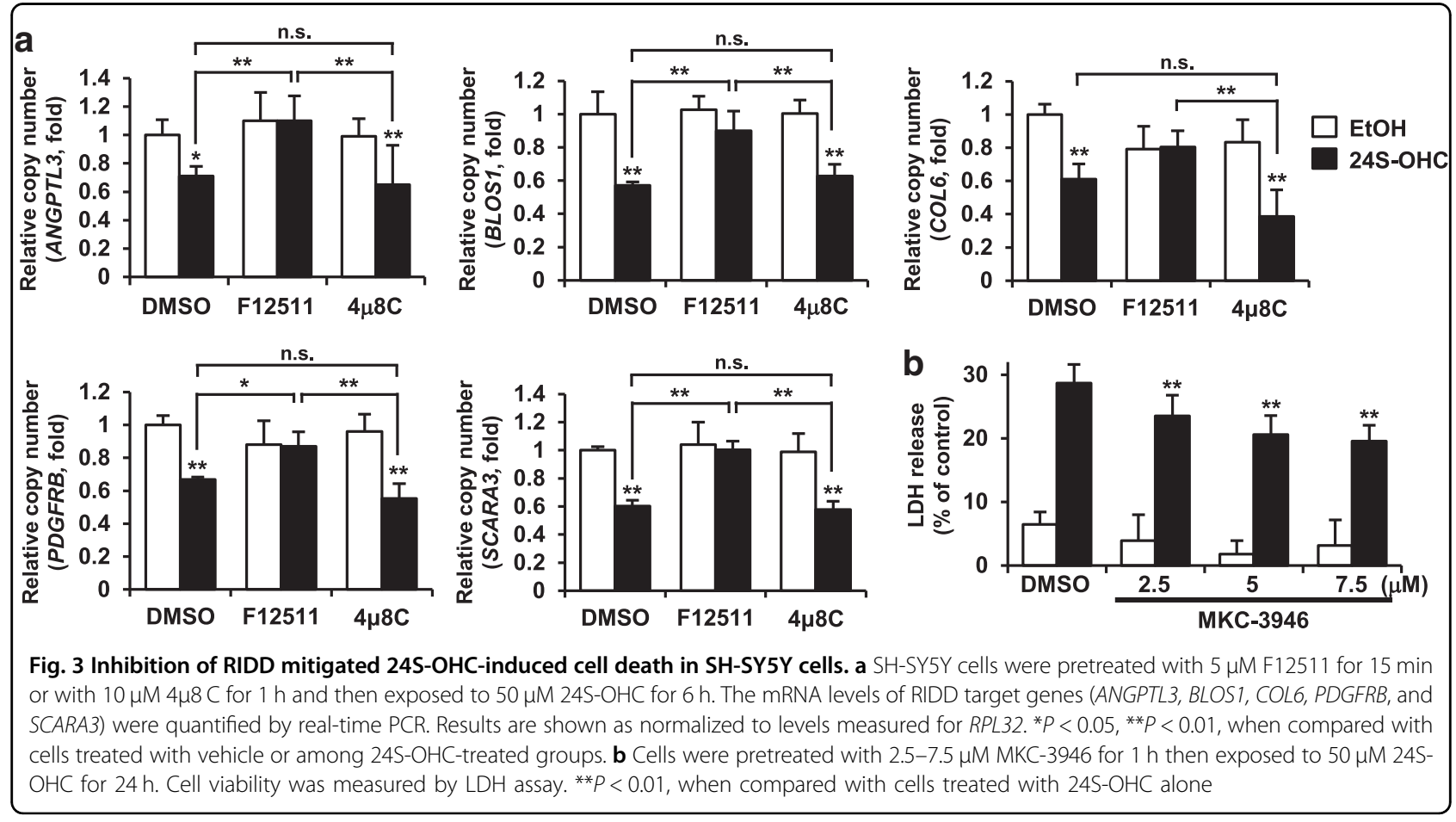


We then sought to evaluate the involvement of IRE1 $\alpha$ mediated RIDD in 24S-OHC-induced cell death. As it had been reported that knockdown of IRE1 $\alpha$ by siRNA induced cell death in SH-SY5Y cells ${ }^{40}$, we therefore first examined the effect of $4 \mu 8 \mathrm{c}$ on $24 \mathrm{~S}-\mathrm{OHC}$-induced downregulation of RIDD substrates. Unlike the inhibitory effect of $4 \mu 8 \mathrm{C}$ observed on IRE1 $\alpha$-mediated XBP1 splicing (Fig. 2f), $10 \mu \mathrm{M}, 4 \mu 8 \mathrm{C}$ did not suppress the downregulation of any gene examined in 24S-OHCtreated cells (Fig. 3a). Although other studies ${ }^{38}$ reported that a high concentration of $4 \mu 8 \mathrm{C}$ is necessary to inhibit RIDD, we found that anything more than $15 \mu \mathrm{M} 4 \mu 8 \mathrm{C}$ had cytotoxic effect on SH-SY5Y cells (data not shown). We therefore chose another inhibitor of IRE1 $\alpha$ RNase activity, i.e., MKC- $3946^{41}$, and found that MKC-3946 significantly inhibited 24S-OHC-induced cell death in a concentration-dependent manner (Fig. 3b). As expected, $7.5 \mu \mathrm{M}$ MKC-3946 significantly blocked the 24S-OHCinduced downregulation of BLOS1 and SCARA3 expression (Fig. S3). Taken together, these results indicated that IRE1 $\alpha$-mediated RIDD plays an important role in the mechanism of 24S-OHC-induced neuronal cell death.

\section{Accumulation of 24S-OHC esters induced disruption of ER membrane integrity in SH-SY5Y cells}

To further examine 24S-OHC-induced ER stress in SHSY5Y cells, we carried out morphological analysis using electron microscopy. To investigate changes in the ER structure during the early stages of 24S-OHC-induced cell death, cells were treated with $50 \mu \mathrm{M} 24 \mathrm{~S}-\mathrm{OHC}$ for $3 \mathrm{~h}$. In contrast to the typical rough ER structures observed in EtOH-treated control cells (Fig. 4a, arrow), we observed broken-membrane ER structures in 24S-OHC-treated cells (Fig. 4a, arrowhead). We therefore assessed whether disturbance of ER membrane integrity was induced by $24 \mathrm{~S}-\mathrm{OHC}$. To do this, we employed crude subcellular fractionation to sequentially extract proteins from cells in a digitonin-soluble fraction enriched for cytosolic protein and in a subsequent NP-40-soluble fraction enriched for membrane-bound organelles including ER. The results showed that in vehicle-treated cells, the cytosolic protein DJ-1 was found in the digitonin extract; we further found that all ER proteins examined were recovered in the NP40 extract (Fig. 4b). In cells treated with $24 \mathrm{~S}-\mathrm{OHC}$ for $3 \mathrm{~h}$, although recovered levels of ER membrane proteins (calnexin and ribophorin-1) in NP-40 extract were unchanged, recovered levels of ER luminal proteins (GRP78, ORP150, protein disulfide isomerase (PDI) and calreticulin) were reduced in the NP-40 extract, but these proteins, except calreticulin, were increased in the DJ-1rich digitonin extract. These changes could be inhibited by cotreatment with F12511, suggesting that ER luminal proteins were released into cytosol as a consequence of 24S-OHC esterification. We also found that levels of
GRP78, ORP150, PDI, and calreticulin were increased in the digitonin extract of cells cotreated with $24 \mathrm{~S}-\mathrm{OHC}$ and MG132 for $6 \mathrm{~h}$, indicating that these proteins were subjected to proteasomal degradation after being released into cytosol (Fig. 4c).

To investigate whether redistribution of ER luminal proteins to cytosol was the result of translocon-mediated retrotranslocation as ERAD substrates, we evaluated the effect of ubiquitination inhibition on 24S-OHC-induced chaperone degradation, because ubiquitination and retrotranslocation of luminal ERAD substrates have been shown to be coordinated by a membrane-embedded E3 ligase complex ${ }^{42}$. To do this, we used TAK-243, which targets the ubiquitin activating enzyme ${ }^{43}$, as a result of which we found that protein ubiquitination was blocked, and that the degradation of p53, a well-studied ubiquitindependent proteasome substrate, was inhibited by TAK243 (Fig. 4d). We further found that cotreatment with TAK-243 did not produce the same drastic inhibition of 24S-OHC-induced chaperone protein degradation (Fig. 4e) as was observed during cotreatment with MG132 (Fig. 1g), suggesting that chaperone proteins were being released into cytosol without ubiquitination.

Collectively, these results suggest that ACAT1mediated 24S-OHC esterification caused disruption of ER membrane integrity, resulting in the release of ER luminal proteins into cytosol, followed by ubiquitinindependent proteasomal degradation of the released proteins.

\section{Global protein synthesis was inhibited by $24 \mathrm{~S}-\mathrm{OHC}$ in SH-SY5Y cells}

We further examined whether $24 \mathrm{~S}$-OHC-induced disruption of ER membrane integrity affected de novo protein synthesis. Because $24 \mathrm{~S}-\mathrm{OHC}$ is known to act as a ligand of liver $\mathrm{X}$ receptor $(\mathrm{LXR})^{18,21}$, we assessed the expression of the LXR target genes ATP-binding cassette transporter $A 1$ (ABCA1) and ABCG1. Real-time PCR results showed that treatment for $6 \mathrm{~h}$ with either $24 \mathrm{~S}$ $\mathrm{OHC}$ or the synthetic LXR ligand T0901317 upregulated expression levels of $A B C A 1$ and $A B C G 1$ mRNA in a concentration-dependent manner (Fig. 5a).

Despite this observed concentration-dependent increase in $A B C G 1$ mRNA expression levels, however, we found that upregulation of ABCG1 protein levels was induced in cells treated with $5 \mu \mathrm{M} 24 \mathrm{~S}-\mathrm{OHC}$ (nontoxic concentration) but not in cells treated with $50 \mu \mathrm{M} 24 \mathrm{~S}-\mathrm{OHC}$ (Fig. $5 \mathrm{~b})$. We further found that cotreatment with $50 \mu \mathrm{M} 24 \mathrm{~S}$ $\mathrm{OHC}$ and F12511 caused ABCG1 protein levels to increase to similar extent as was observed with $5 \mu \mathrm{M} 24 \mathrm{~S}$ $\mathrm{OHC}$, while cotreatment with $50 \mu \mathrm{M} 24 \mathrm{~S}-\mathrm{OHC}$ and MG132 did not induce upregulation of ABCG1 protein. These results suggested that $24 \mathrm{~S}-\mathrm{OHC}$ esterification suppressed ABCG1 protein upregulation not as a result of 


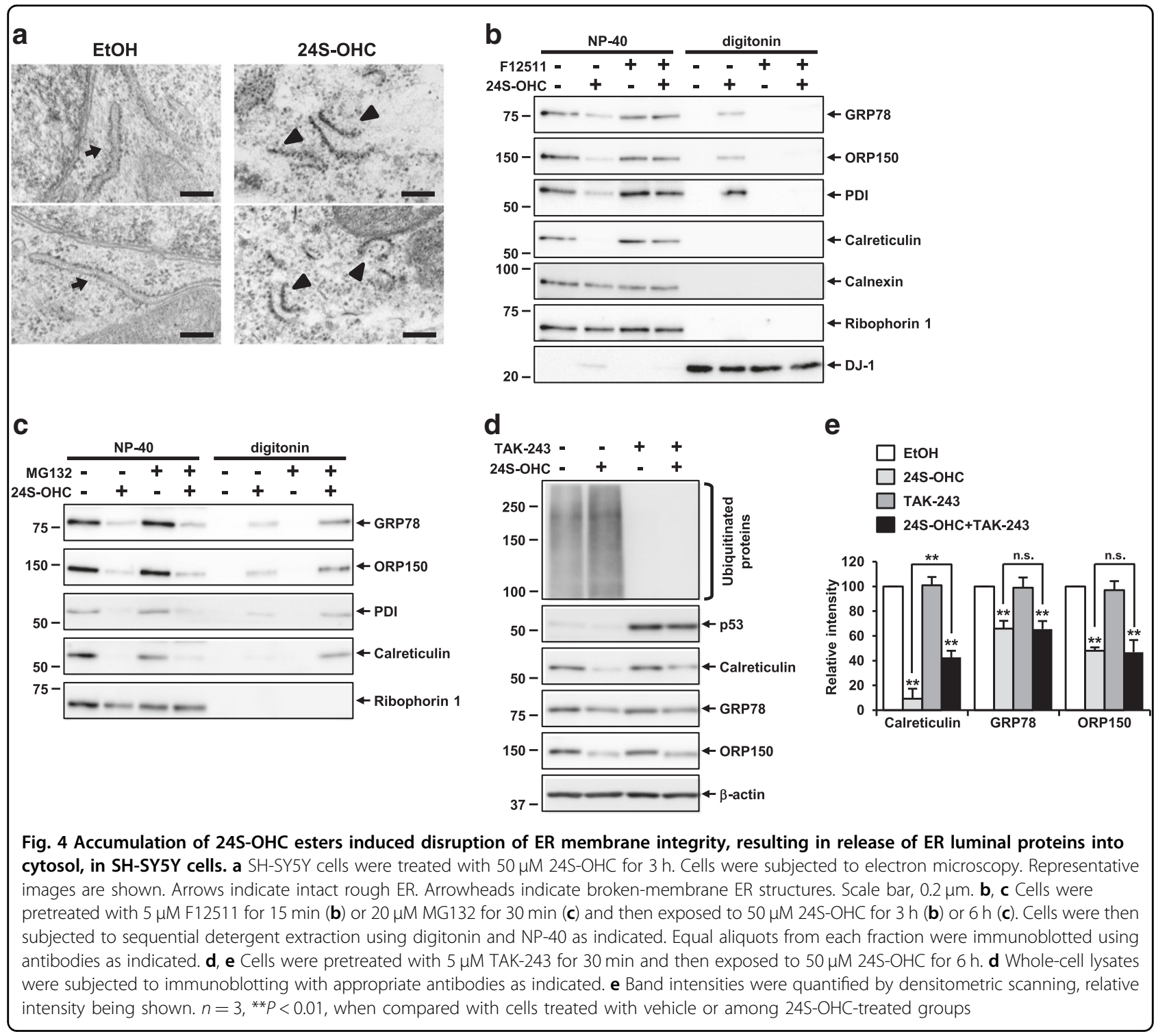

proteasomal degradation, but as a result of inhibition of de novo protein synthesis.

We then evaluated the effect of 24S-OHC esterification on global protein synthesis by using SUnSET, a nonradioactive assay method utilizing incorporation of puromycin into newly synthesized proteins and subsequent detection using anti-puromycin antibody ${ }^{44}$. A robust decrease in puromycin-labeled proteins-not unlike that observed with the known protein synthesis inhibitor cycloheximide (CHX) - was observed in cells treated with 24S-OHC, and this decrease was found to be significantly suppressed by cotreatment with F12511 (Fig. 5c), suggesting that $24 \mathrm{~S}-\mathrm{OHC}$ inhibited not only ABCG1 protein synthesis but also global protein synthesis. Although 24SOHC-induced PERK phosphorylation was completely inhibited by GSK2606414 without affecting IRE1 $\alpha$ phosphorylation or the decrease in calreticulin levels that had been observed, the decrease in levels of puromycinlabeled proteins was partially suppressed by GSK2606414 (Fig. 5d), indicating that the observed 24S-OHC-induced robust decrease in protein synthesis was not only due to PERK-regulated translation attenuation.

\section{Discussion}

It has been indicated that an excess of lipid can induce ER stress. For example, saturated fatty acids can activate the UPR with subsequent induction of apoptosis ${ }^{13,14}$. Moreover, excess cellular cholesterol can activate the UPR, resulting in induction of apoptosis in macrophages $^{45}$. In the case of oxysterol, cytotoxic oxysterols, 

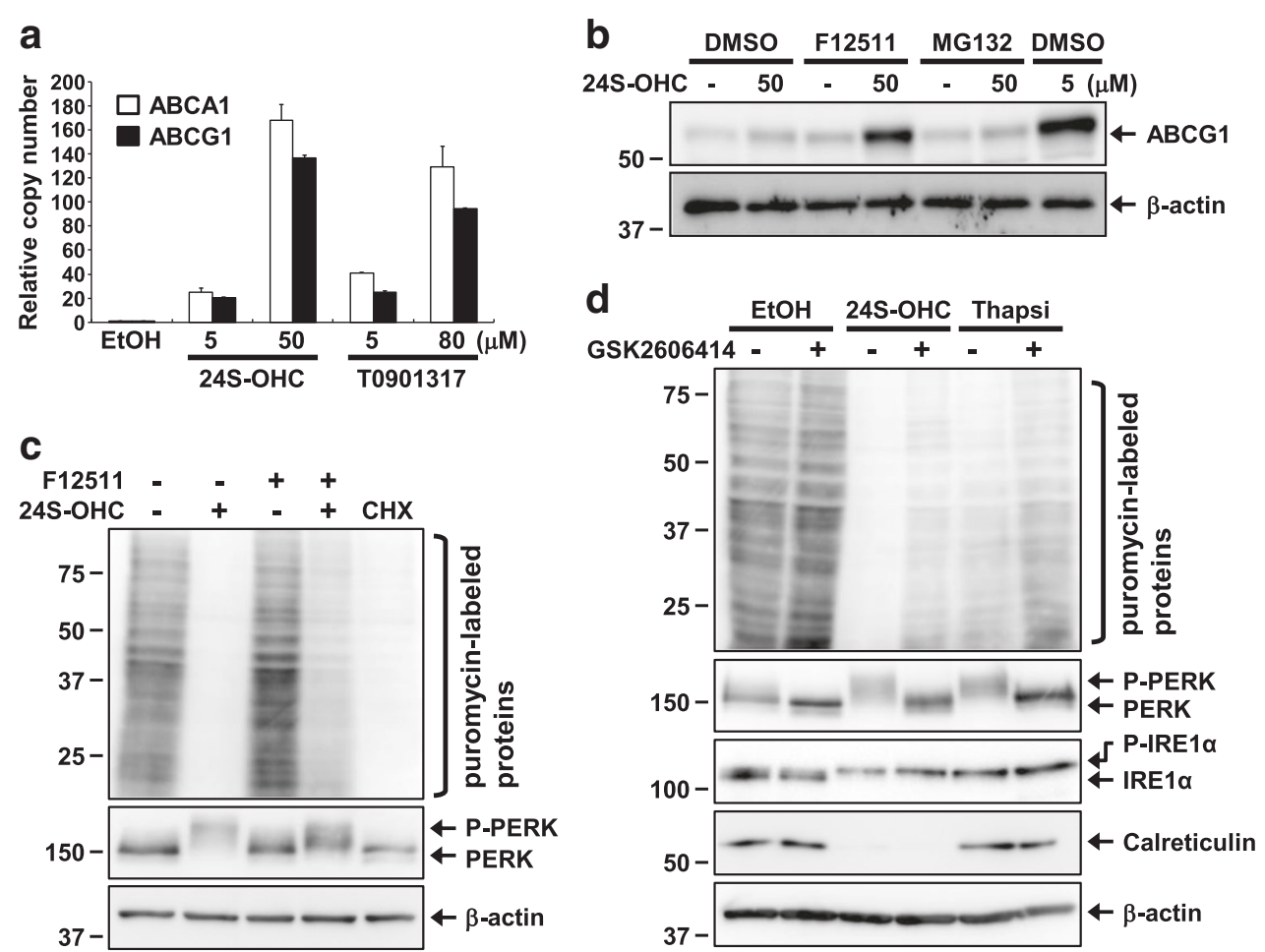

Fig. 5 Global protein synthesis was inhibited by $24 \mathrm{~S}-\mathrm{OHC}$ in SH-SY5Y cells. a SH-SY5Y cells were treated with $24 \mathrm{~S}-\mathrm{OHC}$ ( 5 or $50 \mu \mathrm{M})$ or T0901317 ( 5 or $80 \mu \mathrm{M}$ ) for $6 \mathrm{~h}$. The mRNA levels of $A B C A 1$ and $A B C G 1$ were quantified by real-time PCR. Results are shown as normalized to levels measured for RPL32. b Cells were pretreated with $5 \mu \mathrm{M}$ F12511 or $5 \mu \mathrm{M} \mathrm{MG132}$ for $30 \mathrm{~min}$ and then exposed to 5 or $50 \mu \mathrm{M} 24 \mathrm{~S}-\mathrm{OHC}$ for $6 \mathrm{~h}$. Whole-cell lysates were immunoblotted with antibodies specific for ABCG1 or $\beta$-actin. c Cells were pretreated with or without $5 \mu$ M F12511 for 15 min and then exposed to $50 \mu \mathrm{M} 24 \mathrm{~S}-\mathrm{OHC}$ or $10 \mu \mathrm{g} / \mathrm{ml} \mathrm{CHX}$ for $6 \mathrm{~h}$. d Cells were pretreated with $5 \mu \mathrm{M}$ GSK2606414 for $30 \mathrm{~min}$ and then exposed to $50 \mu \mathrm{M} 24 \mathrm{~S}-\mathrm{OHC}$ or $3 \mu \mathrm{M}$ thapsigargin for $6 \mathrm{~h}$. c, d Cells were then incubated with $10 \mathrm{\mu g} / \mathrm{ml}$ puromycin for last $15 \mathrm{~min}$. Whole-cell lysates were immunoblotted with antibodies specific for puromycin, PERK, IRE1a, calreticulin, or $\beta$-actin

e.g., 7-ketocholesterol, produced by nonenzymatic autooxidation of cholesterol act as stressors to activate the $\mathrm{UPR}^{46}$. In our present study, we showed that enzymatically formed oxysterol $24 \mathrm{~S}-\mathrm{OHC}$ also activates the UPR signaling pathway. Regarding possible mechanisms for 24S-OHC-induced UPR activation, it is thought likely that ER dysfunction due to abnormal morphological change of ER and/or decrease in protein folding capacity causes UPR activation, since our present study demonstrates that 24S-OHC treatment results in a decrease in ER chaperone proteins. As it has been known that GRP78 binds to IRE1, PERK, and ATF6, inhibiting activation of these UPR sensors in unstressed cells, and dissociates from these UPR sensors, activating the UPR during ER stress ${ }^{47}$, it is also possible that reduction of luminal GRP78 levels might enforce UPR activation. Unlike the situation observed with conventional UPR, we found that $24 \mathrm{~S}-\mathrm{OHC}$ treatment resulted in insufficient activation of the prosurvival adaptive response, activating IRE1 and PERK but not ATF6 or XBP1. Regarding to pro-death UPR signaling, we found that RIDD plays an important role in the
24S-OHC-induced cell death machinery (Fig. 6). We postulate that since IRE1 inhibitor cannot by itself suppress $24 \mathrm{~S}$-OHC-induced ER membrane disruption, MKC3946 may have some mild inhibitory effect on cell death.

Most conventional models of LD biogenesis have assumed that the neutral lipids including cholesteryl esters assemble into lens-like structures in the hydrophobic region of the ER membrane bilayer ${ }^{48,49}$. Once the amount of neutral lipids reaches a critical mass, the nascent LD structure buds off from the ER, followed by growth to mature LDs. Based on this model, we posit that newly formed 24S-OHC esters synthesized by ER-resident ACAT1 might be packaged between the two leaflets of the ER membrane bilayer in similar fashion as would be the case with a cholesteryl esters (Fig. 6). Accumulation of 24S-OHC esters results in the formation of LD-like structures. As identified in our previous study ${ }^{33}, 24 S-$ $\mathrm{OHC}$ esters have a hydroxyl group at position 24 in their steroid side chain (e.g., 24S-OHC oleate). More specifically, we postulate that because the $24 \mathrm{~S}-\mathrm{OHC}$ ester has the polar moiety of its side chain plus the nonpolar moiety 


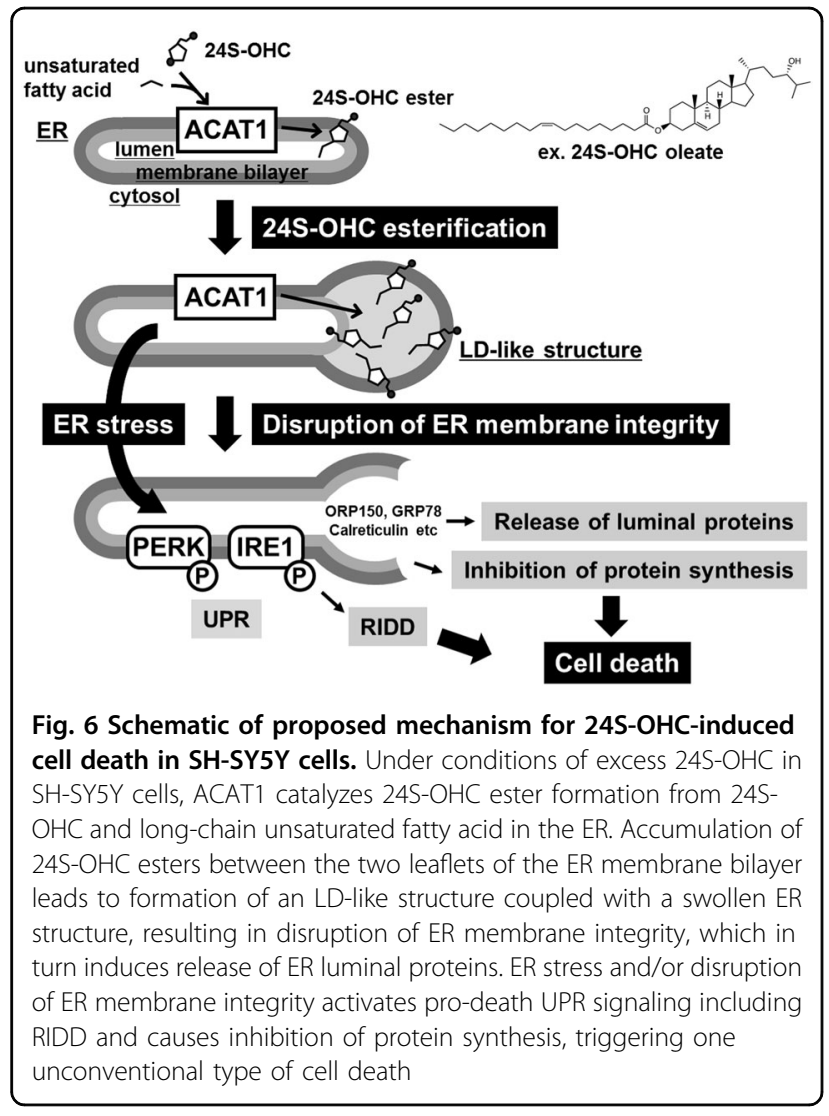

that results from combination of its sterol ring with an unsaturated fatty acid, 24S-OHC esters may possess amphipathic properties within the hydrophobic environment of the lipid bilayer. It is therefore plausible that, unlike cholesteryl esters which are entirely hydrophobic, amphipathic properties of $24 \mathrm{~S}-\mathrm{OHC}$ esters could present a detergent function to the ER bilayer. Indeed, electron microscopy and biochemical analysis revealed that treatment with $24 S-O H C$ caused ER membrane integrity to be disrupted and ER luminal proteins to be subsequently released into cytosol. The possibility that some other proteins mediate 24S-OHC-induced disruption of ER membrane integrity cannot be excluded. It was interesting to note that the released ER proteins were subjected to proteasomal degradation without ubiquitination, suggesting that ubiquitin-independent degradation by the $20 \mathrm{~S}$ proteasome but not ubiquitin-dependent degradation by the $26 \mathrm{~S}$ proteasome might be responsible for degradation of the released proteins. We also found that not only ER luminal proteins but also some ER transmembrane proteins such as calnexin and ATF6 were degraded by proteasome during $24 \mathrm{~S}-\mathrm{OHC}$-induced ER stress. Further studies are needed to clarify the biological mechanism for $24 \mathrm{~S}$-OHC-induced proteasomal degradation of ER proteins.
We also demonstrated that de novo synthesis of global protein was robustly suppressed in 24S-OHC-treated cells, and that the observed decrease in protein synthesis was only partially recovered by PERK inhibitor, suggesting that not only PERK-induced translational attenuation but also other mechanisms might be involved. Since it is wellestablished that global protein synthesis inhibition induces cell death, it is thought that the observed 24S-OHCinduced robust decrease in de novo protein synthesis may play an important role in the cell death machinery. Because we found that mRNA levels of LXR target genes were markedly upregulated in $50 \mu \mathrm{M} 24 \mathrm{~S}$-OHC-treated cells, it is unlikely that the observed robust decrease in nascent proteins was due to reduction in global transcription activity. Degradation of ER-localized mRNAs by RIDD might be partially implicated in the observed decrease in nascent proteins. Because 24S-OHC treatment caused disruption of ER membrane integrity, it is therefore plausible that protein synthesis was downregulated due to disappearance of the scaffold for protein translation at the rough ER. There is a possibility that the weak induction levels of XBP1s, ATF4, and CHOP proteins we observed might be associated with the 24S-OHCinduced robust decrease in protein synthesis.

A growing body of experimental evidence has unveiled and characterized the existence of multiple types of cell death $^{29}$. In addition to apoptosis and necrosis, many nonapoptotic regulated cell death (RCD) pathways are emerging, including necroptosis (regulated necrosis), pyroptosis, parthanatos, ferroptosis, and several others. Furthermore, novel signaling pathways thought to orchestrate RCD are still being characterized. While multiple types of RCD share common morphological hallmarks and are regulated by overlapping and interconnected signaling pathways, the various modes of $\mathrm{RCD}$ are distinguishable to a certain degree based on features observed or inferred to exist during the various stages of the respective cell death processes ${ }^{29,50}$. We have previously demonstrated that SH-SY5Y cells treated with 24S-OHC exhibited neither fragmentation of the nucleus nor caspase activation ${ }^{28}$. We have also found that $24 \mathrm{~S}$ OHC-treated cells showed morphological changes resembling necrosis, but these did not induce ATP depletion $^{28}$. We might summarize the results of our current and previous findings by saying that the mode of 24S-OHC-induced cell death in SH-SY5Y cells is characterized by: (i) ACAT-mediated $24 \mathrm{~S}-\mathrm{OHC}$ esterificationdependency; (ii) activation of pro-death UPR signaling including RIDD; (iii) disruption of ER membrane integrity; and (iv) inhibition of protein synthesis (Fig. 6). Based on this unique combination of features, we conclude that $24 S$-OHC-induced cell death might be an unconventional type of RCDs. Since it has been reported that RIPK1 is a mediator of ER stress-induced apoptosis ${ }^{51}$, the 
dependency with respect to RIPK1 suggests a possible connection with the downstream branch of 24S-OHCinduced cell death signaling. Moreover, we have shown that accumulation of $24 \mathrm{~S}-\mathrm{OHC}$ esters induces caspasedependent apoptotic cell death in Jurkat cells or all-transretinoic acid-treated $\mathrm{SH}-\mathrm{SY} 5 \mathrm{Y}$ cells in which caspase-8 is expressed $^{32,52}$, suggesting that the executor(s) in the downstream pathway(s) of 24S-OHC-induced cell death may exhibit cell-type dependency. In studies with other oxysterols, we previously showed that 7-ketocholesterol, $7 \alpha-\mathrm{OHC}, 7 \beta-\mathrm{OHC}$, and $22 \mathrm{R}-\mathrm{OHC}$ induced cell death in SH-SY5Y cells, and that this was not suppressed by ACAT inhibitor $^{32}$. On the other hand, ACAT is implicated in 24 (S),25-epoxycholesterol-induced apoptosis in mast cells ${ }^{53}$, and in 7-ketocholesterol-induced apoptosis in macrophage $^{54}$. Since growing evidence suggests a link between accumulation of oxysterols and the pathophysiologies of various diseases ${ }^{55,56}$, further investigations will be required to address the features and specificities of $24 \mathrm{~S}$ $\mathrm{OHC}$-induced cell death in oxysterol-induced cell death. In conclusion, our present study revealed that abnormal ER morphological change with disruption of ER membrane integrity is crucial for triggering of pro-death signaling under conditions in which there is accumulation of 24S-OHC esters by ACAT1.

\section{Materials and methods Materials}

24S-OHC was synthesized as we previously reported ${ }^{57}$, this have been dissolved in EtOH (Wako, Osaka, Japan) and stored at $-20^{\circ} \mathrm{C}$. F12511 ACAT inhibitor was the generous gift of Dr. Ta-Yuan Chang (Geisel School of Medicine at Dartmouth, Hanover, NH, USA). Thapsigargin, MG132, and CHX were purchased from Wako (Osaka, Japan). Nec-1, SP600125, and 4-PBA were from Sigma-Aldrich (St. Louis, MO, USA). $4 \mu 8 \mathrm{C}$ and MKC3946 were from Merck Millipore (Darmstadt, Germany). GSK2606414, T0901317, NQDI-1, and SB203580 were from Cayman Chemical (Ann Arbor, MI, USA). TAK-243 was from Active Biochem (Hong Kong, China). Thapsigargin, MG132, Nec-1, GSK2606414, 4 48 C, T0901317, TAK-243, CHX, NQDI-1, SB203580, and SP600125 were dissolved in dimethyl sulfoxide (DMSO, Wako). 4-PBA was dissolved in $1 \mathrm{M} \mathrm{NaOH}$. The following antibodies were from commercial sources: IRE1 $\alpha \alpha$ (Cat\# 3294), PERK (Cat\# 3192), ATF4 (Cat\# 11815), and CHOP (Cat\# 2895) were all from Cell Signaling (Danvers, MA, USA); ATF6 $\alpha$ (Cat\# 73500) was from BioAcademia (Osaka, Japan); $\beta$-actin (Cat\# A5441) was from Sigma-Aldrich. XBP1 (Cat\# 24168-1-AP) was from Proteintech (Chicago, IL, USA); GRP78 (Cat\# 610979), calreticulin (Cat\# 612136), calnexin (Cat\# 610523), and (PDI Cat\# 610946) were from BD Biosciences (Franklin Lakes, NJ, USA); ORP150 (Cat\# 10301) was from IBL (Gunma, Japan); ribophorin 1 (Cat\# sc-12614), ubiquitin (Cat\# sc-8017), and DJ-1 (Cat\# ab4150) were from Abcam (Cambridge, UK); p53 (Cat\# OP43) and puromycin (Cat\# MABE343) were from Merck Millipore; ABCG1 (Cat\# NB400-132) was from Novus Biologicals (Littleton, CO, USA). All other chemicals, of analytical grade, were obtained from Sigma-Aldrich or Wako.

\section{Cell lines and cell culture}

Human neuroblastoma cells from the SH-SY5Y cell line were purchased from American Type Culture Collection (Manassas, VA, USA) or European Collection of Cell Cultures (Salisbury, UK). Cells were routinely maintained in the Dulbecco's Modified Eagle's Medium/Nutrient Mixture Ham's F-12 (Thermo Fisher Scientific, Waltham, MA, USA), which contained $10 \%$ heat-inactivated fetal bovine serum (Sigma-Aldrich), and antibiotics $(100 \mathrm{U} / \mathrm{ml}$ penicillin, $100 \mu \mathrm{g} / \mathrm{ml}$ streptomycin; Thermo Fisher Scientific). Cells were grown at $37^{\circ} \mathrm{C}$ under an atmosphere of $95 \%$ air and $5 \% \mathrm{CO}_{2}$.

\section{Cell treatment}

To elucidate the mechanism of 24S-OHC-induced cell death, SH-SY5Y cells were treated with $50 \mu \mathrm{M}$ 24S-OHC for the indicated period (final concentration of $\mathrm{EtOH}$ in the medium was $0.5 \%$ ). Cells were also exposed to $3 \mu \mathrm{M}$ thapsigargin for the indicated period as positive controls. EtOH or DMSO was used as a vehicle for control treatments. To evaluate the effect of various inhibitors, cells were pretreated with $5 \mu \mathrm{M}$ F12511 for $15 \mathrm{~min}$, or with $20 \mu \mathrm{M}$ MG132, or with $5 \mu \mathrm{M}$ TAK-243 for $30 \mathrm{~min}$, before further treatment. Cells were also pretreated with variable concentrations of GSK2606414, 4 48 C, MKC-3946, NQDI-1, SB203580, or SP600125 for $1 \mathrm{~h}$, or 4-PBA for $24 \mathrm{~h}$, before further treatment.

\section{Immunoblotting}

Whole-cell extract was prepared as described previously $^{58}$. Briefly, cells were suspended in lysis buffer $(150 \mathrm{mM} \mathrm{NaCl}, 50 \mathrm{mM}$ Tris- $\mathrm{HCl}$ at $\mathrm{pH} 7.5,1 \% \mathrm{NP}-40$, $2 \mathrm{mM}$ EDTA) containing PhosSTOP (Roche Applied Science, Mannheim, Germany) and a protease inhibitor cocktail (Nacalai Tesque, Kyoto, Japan) at $4{ }^{\circ} \mathrm{C}$ for $30 \mathrm{~min}$. Nuclei and unlysed cellular debris were removed by centrifugation at $13,000 \times g$ for $5 \mathrm{~min}$. Protein samples were subjected to SDS-PAGE and were transferred to a PVDF membrane for $1 \mathrm{~h}$ at $100 \mathrm{~V}$. Immunoblotting with appropriate antibodies was visualized with enhanced chemiluminescence (Millipore, Billerica, MA, USA).

\section{XBP1-splicing assay}

The total RNA isolation and real-time PCR were conducted as described previously ${ }^{20}$. Briefly, the total RNA was isolated by using Tripure Isolation Reagent (Roche 
Applied Science) along with chloroform according to the manufacturer's instructions. Synthesis of cDNA was carried out using a PrimeScript ${ }^{\mathrm{TM}}$ RT Master Mix (Takara Bio, Shiga, Japan) according to the manufacturer's instruction. The XBP1-splicing assay used human XBP1specific primers that amplified and spliced (-26 nt) and unspliced XBP1 mRNA (forward 5'-TTACGAGAGA AAACTCATGGCC-3', reverse 5'-GGGTCCAAGTTGTC CAGAATGC-3'). PCR products were analyzed on a $3 \%$ agarose gel.

\section{Determination of cell viability}

For determination of cell viability, WST-8 assay and lactate dehydrogenase (LDH) assay were used. WST-8 assay was performed using Cell Counting Kit-8 according to the manufacturer's instructions (Dojindo, Kumamoto, Japan). LDH activity assay was performed as described previously $^{30}$. The data are expressed as the percentage of total LDH activity, after subtraction of background determined from the culture medium alone.

\section{Knockdown of CHOP by small interfering RNA}

Double-stranded small interfering RNAs (siRNA) targeting human $C H O P$ were obtained from Thermo Fisher Scientific. The sense and antisense of siRNA specific for CHOP used here were as follows: \#1: 5'-UAGCUGAAG AGAAUGAACGGCUCAA-3' and 5'-UUGAGCCGUUC AUUCUCUUCAGCUA-3'; \#2: 5'-GCAAGAGGUCCUG UCUUCAGAUGAA-3' and 5'-UUCAUCUGAAGACAG GACCUCUUGC-3'; \#3: 5'-UAGAGGCGACUCGCCGA GCUCUGAU-3' and 5'-AUCAGAGCUCGGCGAGUCG CCUCUA-3'. Stealth RNAi-negative control (NC) with medium GC content (48\%) was obtained from Thermo Fisher Scientific. The siRNAs were transfected into SHSY5Y cells at a concentration of $100 \mathrm{pmol} /$ well by Lipofectamine RNAiMAX (Thermo Fisher Scientific) for $24 \mathrm{~h}$ before further experiments. To confirm knockdown efficiency for CHOP, expression levels of protein were analyzed by immunoblotting analysis.

\section{Real-time PCR}

Quantitative detection of differentially expressed genes was performed with the 7900HT Fast Real-Time PCR system (Applied Biosystems, Foster City, CA, USA) and SYBR Green Master Mix (Thermo Fisher Scientific) under the following condition: one cycle of $95^{\circ} \mathrm{C}$ for $10 \mathrm{~min}$ followed by 40 cycles of $95^{\circ} \mathrm{C}$ for $15 \mathrm{~s}$ and $60^{\circ} \mathrm{C}$ for $1 \mathrm{~min}$. Human RPL32 (ribosomal protein L32) was used for the normalization of each reaction. The following primers (Thermo Fisher Scientific) were used: human ANGPTL3 forward 5'-A ACATGATGGCATTCCTGCTGA-3', reverse 5'-GAGTT GCTGGGTCTGATGGCA-3'; human BLOS1 forward 5'-G AGGAGGCGAGAGGCTATCA-3', reverse 5'-ATCCCCA ATTTCCTTGAGTGC-3'; human COL6 forward 5'-CA
ACGACATTGCACCCCGAG-3', reverse 5'-CCGCACTT GCATTCACAGCA-3'; human PDGFRB forward 5'-CAGC AAGGACACCATGCGGC-3', reverse 5'-TGGGACATCC GTTCCCACAC-3'; human SCARA3 forward 5'-ACGAGG ACATGCCGACCTTC-3', reverse 5'-TTCAGGGCTTTC GGATCCAGG-3'; human RPL32 forward 5'-CCCCTT GTGAAGCCCAAGA-3', reverse 5'-TGACTGGTGCCGG ATGAAC-3'.

\section{Electron microscopy analysis}

For electron microscopy, ultrathin sections were prepared as described previously ${ }^{33}$, and were subjected to TEM observation (JEM-1200 EX, JEOL) at Hanaichi Ultrastructure Research Institute (Okazaki, Japan).

\section{Subcellular fractionation}

Crude cytosolic and membrane/organelle fractions were isolated by sequential detergent extraction as described previously ${ }^{59,60}$. Equal aliquots from each fractions were analyzed for immunoblotting.

\section{Measurement of protein synthesis by SUnSET puromycin end-labeling assay}

Following treatment, cells were incubated with $10 \mu \mathrm{g} / \mathrm{ml}$ puromycin for $15 \mathrm{~min}$ prior to cell lysis. Whole-cell lysates were then subjected to immunoblotting. An antipuromycin antibody was used to detect levels of puromycin-labeled proteins.

\section{Statistical analysis}

The data are reported as mean \pm SD of at least three independent experiments unless otherwise indicated. The statistical significance of the difference between the determinations was calculated by analysis of variance using ANOVA, Tukey-Kramer multiple comparisons test. The difference was considered significant when the $P$-value was $<0.05$.

\section{Acknowledgements \\ We thank Dr. Ta-Yuan Chang (Geisel School of Medicine at Dartmouth, NH, USA) and Kowa Co. Ltd (Aichi, Japan) for providing valuable reagents. We also thank Norie Kato for research support and also thank Gerry Peters (JTT K.K., Takatsuki, Japan) for his careful editing of the paper. This work was supported in part by JSPS KAKENHI Grant-in-Aid for Scientific Research (C) 16K08254 and $19 K 07093$ to Y.U., 16 K00882 to N.N., and the MEXT-Supported Program for the Strategic Research Foundation at Private Universities in Japan for years 2012-2016 and 2015-2019.}

Conflict of interest

The authors declare that they have no conflict of interest.

\section{Publisher's note}

Springer Nature remains neutral with regard to jurisdictional claims in published maps and institutional affiliations.

The online version of this article (https://doi.org/10.1038/s41420-019-0192-4) contains supplementary material, which is available to authorized users. 
Received: 1 February 2019 Revised: 20 May 2019 Accepted: 30 May 2019 Published online: 05 July 2019

\section{References}

1. Hetz, C. The unfolded protein response: controlling cell fate decisions under ER stress and beyond. Nat. Rev. Mol. Cell. Biol. 13, 89-102 (2012).

2. Moore, K. A. \& Hollien, J. The unfolded protein response in secretory cell function. Annu. Rev. Genet. 46, 165-183 (2012).

3. Kim, I., Xu, W. \& Reed, J. C. Cell death and endoplasmic reticulum stress: disease relevance and therapeutic opportunities. Nat. Rev. Drug Discov. 7, 1013-1030 (2008)

4. Tabas, I. \& Ron, D. Integrating the mechanisms of apoptosis induced by endoplasmic reticulum stress. Nat. Cell Biol. 13, 184-190 (2011).

5. Sano, R. \& Reed, J. C. ER stress-induced cell death mechanisms. Biochim. Biophys. Acta 1833, 3460-3470 (2013).

6. Iurlaro, R. \& Munoz-Pinedo, C. Cell death induced by endoplasmic reticulum stress. FEBS J. 283, 2640-2652 (2016).

7. Hollien, J. \& Weissman, J. S. Decay of endoplasmic reticulum-localized mRNAs during the unfolded protein response. Science 313, 104-107 (2006).

8. Hetz, C., Chevet, E. \& Harding, H. P. Targeting the unfolded protein response in disease. Nat. Rev. Drug Discov. 12, 703-719 (2013).

9. Maurel, M., Chevet, E., Tavernier, J. \& Gerlo, S. Getting RIDD of RNA: IRE1 in cell fate regulation. Trends Biochem. Sci. 39, 245-254 (2014).

10. Tam, A. B., Koong, A. C. \& Niwa, M. Ire1 has distinct catalytic mechanisms for XBP1/HAC1 splicing and RIDD. Cell Rep. 9, 850-858 (2014).

11. Liu, Z., LV, Y., Zhao, N., Guan, G. \& Wang, J. Protein kinase R-like ER kinase and its role in endoplasmic reticulum stress-decided cell fate. Cell Death Dis. 6 , e1822 (2015)

12. Oyadomari, S. \& Mori, M. Roles of CHOP/GADD153 in endoplasmic reticulum stress. Cell Death Differ. 11, 381-389 (2004).

13. Ariyama, H., Kono, N., Matsuda, S., Inoue, T. \& Arai, H. Decrease in membrane phospholipid unsaturation induces unfolded protein response. J. Biol. Chem. 285, 22027-22035 (2010).

14. Halbleib, K. et al. Activation of the unfolded protein response by lipid bilayer stress. Mol. Cell 67, 673-684 e8 (2017).

15. Noguchi, N., Saito, Y. \& Urano, Y. Diverse functions of 24(S)-hydroxycholesterol in the brain. Biochem. Biophys. Res. Commun. 446, 692-696 (2014).

16. Dietschy, J. M. Central nervous system: cholesterol turnover, brain development and neurodegeneration. J. Biol. Chem. 390, 287-293 (2009).

17. Lütjohann, D. et al. Cholesterol homeostasis in human brain: evidence for an age-dependent flux of 24S-hydroxycholesterol from the brain into the circulation. Proc. Natl Acad. Sci. USA 93, 9799-9804 (1996).

18. Russell, D. W., Halford, R. W., Ramirez, D. M., Shah, R. \& Kotti, T. Cholesterol 24hydroxylase: an enzyme of cholesterol turnover in the brain. Annu. Rev. Biochem. 78, 1017-1040 (2009).

19. Jeitner, T. M., Voloshyna, I. \& Reiss, A. B. Oxysterol derivatives of cholesterol in neurodegenerative disorders. Curr. Med. Chem. 18, 1515-1525 (2011).

20. Urano, Y., Ochiai, S. \& Noguchi, N. Suppression of amyloid-beta production by 24S-hydroxycholesterol via inhibition of intracellular amyloid precursor protein trafficking. FASEB J. 27, 4305-4315 (2013).

21. Okabe, A. et al. Adaptive response induced by 24S-hydroxycholesterol through liver $X$ receptor pathway reduce 7-ketocholesterol-caused neuronal cell death. Redox Biol. 2, 28-35 (2014).

22. Noguchi, N., Urano, Y., Takabe, W. \& Saito, Y. New aspects of 24(S)-hydroxycholesterol in modulating neuronal cell death. Free Radic. Biol. Med. 87, 366-372 (2015).

23. Sun, M. Y. et al. 24(S)-Hydroxycholesterol as a modulator of neuronal signaling and survival. Neuroscientist 22, 132-144 (2016)

24. Lütjohann, D. et al. Plasma 24S-hydroxycholesterol (cerebrosterol) is increased in Alzheimer and vascular demented patients. J. Lipid Res. 41, 195-198 (2000).

25. Shafaati, M., Solomon, A., Kivipelto, M., Björkhem, I. \& Leoni, V. Levels of ApoE in cerebrospinal fluid are correlated with Tau and 24S-hydroxycholesterol in patients with cognitive disorders. Neurosci. Lett. 425, 78-82 (2007).

26. Björkhem, I. et al. Oxysterols and Parkinson's disease: evidence that levels of 24S-hydroxycholesterol in cerebrospinal fluid correlates with the duration of the disease. Neurosci. Lett. 555, 102-105 (2013).
27. Kölsch, H., Lütjohann, D., Tulke, A., Björkhem, I. \& Rao, M. L. The neurotoxic effect of 24-hydroxycholesterol on SH-SY5Y human neuroblastoma cells. Brain Res. 818, 171-175 (1999)

28. Yamanaka, K., Saito, Y., Yamamori, T., Urano, Y. \& Noguchi, N. 24(S)-hydroxycholesterol induces neuronal cell death through necroptosis, a form of programmed necrosis. J. Biol. Chem. 286, 24666-24673 (2011).

29. Galluzzi, L. et al. Molecular mechanisms of cell death: recommendations of the Nomenclature Committee on Cell Death. Cell Death Differ. 25, 486-541 (2018).

30. Vo, D. K., Urano, Y., Takabe, W., Saito, Y. \& Noguchi, N. 24(S)-Hydroxycholesterol induces RIPK1-dependent but MLKL-independent cell death in the absence of caspase-8. Steroids 99, 230-237 (2015).

31. Chang, T. Y., Li, B. L., Chang, C. C. \& Urano, Y. Acyl-coenzyme A: cholesterol acyltransferases. Am. J. Physiol. Endocrinol. Metab. 297, E1-E9 (2009).

32. Yamanaka, K., Urano, Y., Takabe, W., Saito, Y. \& Noguchi, N. Induction of apoptosis and necroptosis by 24(S)-hydroxycholesterol is dependent on activity of acyl-CoA:cholesterol acyltransferase 1. Cell Death Dis. 5, e990 (2014).

33. Takabe, W. et al. Esterification of $245-\mathrm{OHC}$ induces formation of atypical lipid droplet-like structures, leading to neuronal cell death. J. Lipid Res. 57, 2005-2014 (2016)

34. Thuerauf, D. J., Morrison, L. E., Hoover, H. \& Glembotski, C. C. Coordination of ATF6-mediated transcription and ATF6 degradation by a domain that is shared with the viral transcription factor, VP16. J. Biol. Chem. 277, 20734-20739 (2002).

35. Marwarha, G., Dasari, B. \& Ghribi, O. Endoplasmic reticulum stress-induced CHOP activation mediates the down-regulation of leptin in human neuroblastoma SH-SY5Y cells treated with the oxysterol 27-hydroxycholesterol. Cell. Signal. 24, 484-492 (2012).

36. Zamarbide, M. et al. Phenyl acyl acids attenuate the unfolded protein response in tunicamycin-treated neuroblastoma cells. PLOS ONE 8, e71082 (2013).

37. Hollien, J. et al. Regulated Ire1-dependent decay of messenger RNAs in mammalian cells. J. Cell Biol. 186, 323-331 (2009).

38. Cross, B. C. et al. The molecular basis for selective inhibition of unconventional mRNA splicing by an IRE1-binding small molecule. Proc. Natl Acad. Sci. USA 109, E869-E878 (2012).

39. So, J. S. et al. Silencing of lipid metabolism genes through IRE1alpha-mediated mRNA decay lowers plasma lipids in mice. Cell Metab. 16, 487-499 (2012).

40. Son, S. M., Byun, J., Roh, S. E., Kim, S. J. \& Mook-Jung, I. Reduced IRE1alpha mediates apoptotic cell death by disrupting calcium homeostasis via the InsP3 receptor. Cell Death Dis. 5, e1188 (2014).

41. Mimura, N. et al. Blockade of XBP1 splicing by inhibition of IRE1alpha is a promising therapeutic option in multiple myeloma. Blood 119, 5772-5781 (2012).

42. Ruggiano, A., Foresti, O. \& Carvalho, P. Quality control: ER-associated degradation: protein quality control and beyond. J. Cell Biol. 204, 869-879 (2014).

43. Hyer, M. L. et al. A small-molecule inhibitor of the ubiquitin activating enzyme for cancer treatment. Nat. Med. 24, 186-193 (2018).

44. Schmidt, E. K., Clavarino, G., Ceppi, M. \& Pierre, P. SUnSET, a nonradioactive method to monitor protein synthesis. Nat. Methods 6, 275-277 (2009).

45. Feng, B. et al. The endoplasmic reticulum is the site of cholesterol-induced cytotoxicity in macrophages. Nat. Cell Biol. 5, 781-792 (2003).

46. Pedruzzi, E. et al. NAD(P)H oxidase Nox-4 mediates 7-ketocholesterol-induced endoplasmic reticulum stress and apoptosis in human aortic smooth muscle cells. Mol. Cell Biol. 24, 10703-10717 (2004).

47. Shen, J., Chen, X., Hendershot, L. \& Prywes, R. ER stress regulation of ATF6 localization by dissociation of BiP/GRP78 binding and unmasking of Golgi localization signals. Dev. Cell 3, 99-111 (2002).

48. Walther, T. C. \& Farese, R. V. Jr. Lipid droplets and cellular lipid metabolism. Annu. Rev. Biochem. 81, 687-714 (2012).

49. Ohsaki, Y. et al. Biogenesis of cytoplasmic lipid droplets: from the lipid ester globule in the membrane to the visible structure. Biochim. Biophys. Acta 1791 399-407 (2009).

50. Vanden Berghe, T., Linkermann, A., Jouan-Lanhouet, S., Walczak, H. \& Vandenabeele, P. Regulated necrosis: the expanding network of non-apoptotic cell death pathways. Nat. Rev. Mol. Cell Biol. 15, 135-147 (2014).

51. Estornes, Y. et al. RIPK1 promotes death receptor-independent caspase-8mediated apoptosis under unresolved ER stress conditions. Cell Death Dis. 5 e1555 (2014). 
52. Nakazawa, T. et al. Effect of vitamin E on 24(S)-hydroxycholesterol-induced necroptosis-like cell death and apoptosis. J. Steroid Biochem. Mol. Biol. 169, 69-76 (2017).

53. Fukunaga, M. et al. Mast cell death induced by 24(S),25-epoxycholesterol. Exp. Cell Res. 316, 3272-3281 (2010)

54. Freeman, N. E. et al. Acyl-coenzyme A:cholesterol acyltransferase promotes oxidized LDL/oxysterol-induced apoptosis in macrophages. J. Lipid Res. 46, 1933-1943 (2005).

55. Poli, G., Biasi, F. \& Leonarduzzi, G. Oxysterols in the pathogenesis of major chronic diseases. Redox Biol. 1, 125-130 (2013).

56. Luu, W., Sharpe, L. J., Capell-Hattam, I., Gelissen, I. C. \& Brown, A. J. Oxysterols: old tale, new twists. Annu. Rev. Pharmacol. Toxicol. 56, 447-467 (2016).
57. Shibuya, K. et al. Synthesis of 24(S)-hydroxycholesterol esters responsible for the induction of neuronal cell death. Bioorg. Med. Chem. 24 2559-2566 (2016).

58. Kotani, R., Urano, Y., Sugimoto, H. \& Noguchi, N. Decrease of amyloid- $\beta$ levels by curcumin derivative via modulation of amyloid- $\beta$ protein precursor trafficking. J. Alzheimers Dis. 56, 529-542 (2017).

59. Holden, P. \& Horton, W. A. Crude subcellular fractionation of cultured mammalian cell lines. BMC Res. Notes 2, 243 (2009).

60. Urano, Y. et al. 6-Hydroxydopamine induces secretion of PARK7/DJ-1 via autophagy-based unconventional secretory pathway. Autophagy $\mathbf{1 4}$ 1943-1958 (2018). 